\title{
MEMORY, MEDICINE AND CHILDHOOD IN MIDDLE AGE
}

\author{
Ana Maria Rodrigues de Oliveira \\ Universidade Nova de Lisboa \\ PoRTugal
}

Date of receipt: $30^{\text {th }}$ of August, 2018

Finale date of acceptance: $6^{\text {th }}$ of May, 2019

\section{Abstract}

In this article we will follow the medieval childhood since the caring of the expecting mothers to the first foods, steps, movements, words and diseases of children. Medieval medical treaties play an important role throughout all this process.

KeYWORDS

Middle Ages, Children, Medicine.

Capitalia Verba

Medium Aevum, Pueri, Medicina. 
According to the medieval conception of the world and society, motherhood was so important in woman's everyday life as marriage or family origins. The principal woman's purpose in life was to get pregnant and have babies. Lack of children was seen as misfortune. Although different forms of contraception and abortifacients are known to have existed, ${ }^{1}$ childbearing was the central focus of a married woman's life. Marriage and procreation constituted moral obligations of spouses, especially for the woman, since to have children represented the possibility of being rescued from the Eve's sin. To bring children into the world, continuously until death was, beyond virginity, as the Dominican Nicolau de Gorran (d.1295) recalled, the only way for the woman to achieve salvation. ${ }^{2}$

The twelfth century can perhaps be pointed as the period in which the image of motherhood changed subtly. As the church promoted the cult of the Holy Mother, multiplying and diversifying the representations of Mary as a mother, motherhood acquired higher status as well. The Virgins of Expectation or of Childbirth are one of the visible aspects of this change, since they contributed to associate Blessed Virgin not only with motherhood but also with the pregnancy itself. In churches, the mother of Christ was seen as the pregnant woman who caressed her prominent belly with one hand, while, with the other, greeted or blessed her devotees (see figure 1). Like the Virgin, pregnant women should be socially respected and honoured. The Virgins of Milk also contributed to the evaluation of maternity by giving special importance to maternal breastfeeding (see figure 2). Likewise the images of the Holy Mothers, based on the maternal genealogy of Christ, emphasized the contribution of women to family reproduction (see figure 3 ).

A woman could become a mother very early in her own lifetime. The age of majority for girls was around twelve years in most parts of the Mediterranean. Whether this was an accurate reflection of the average age of menarche is unclear, but given the universal distaste evinced in legal texts towards underage marriage, the completion of the twelfth year must have carried some connotation of sexual maturity. ${ }^{3}$ Isidore of Seville, in the seventh century, stated that girls could be married at any time after menarche. ${ }^{4}$

Though giving birth and bringing up children was the 'role' of married women, this does not mean that the mysteries of 'female production' did not represent an area that was almost always kept to women, being rarely addressed by some literate medieval culture, which was predominantly male. In fact, both pregnancy and childbirth or child care were still considered female and private affairs and functions, to which men had little access. The knowledge of what was happening

1. Rodrigues Oliveira, Ana. A Criança na Sociedade Medieval Portuguesa. Lisbon: Teorema, 2007: 78-85.

2. Vecchio, Silvana. "A boa esposa", História das Mulheres, 5 vols., Georges Duby, Michelle Perrot, eds. Porto: Afrontamento, 1993: II, 163.

3. Rodrigues Oliveira, Ana. O dia-a-dia em Portugal na Idade Média. Lisbon: A Esfera dos Livros, 2015: 257-258.

4. Hispalensis, Sanctus Isidorus. “De Ecclesiasticis Officiis”, Patrologiae. Cursus completus, Paris: J. P. Migne editorem, 1862, LXXXIII, col. 811-812. 

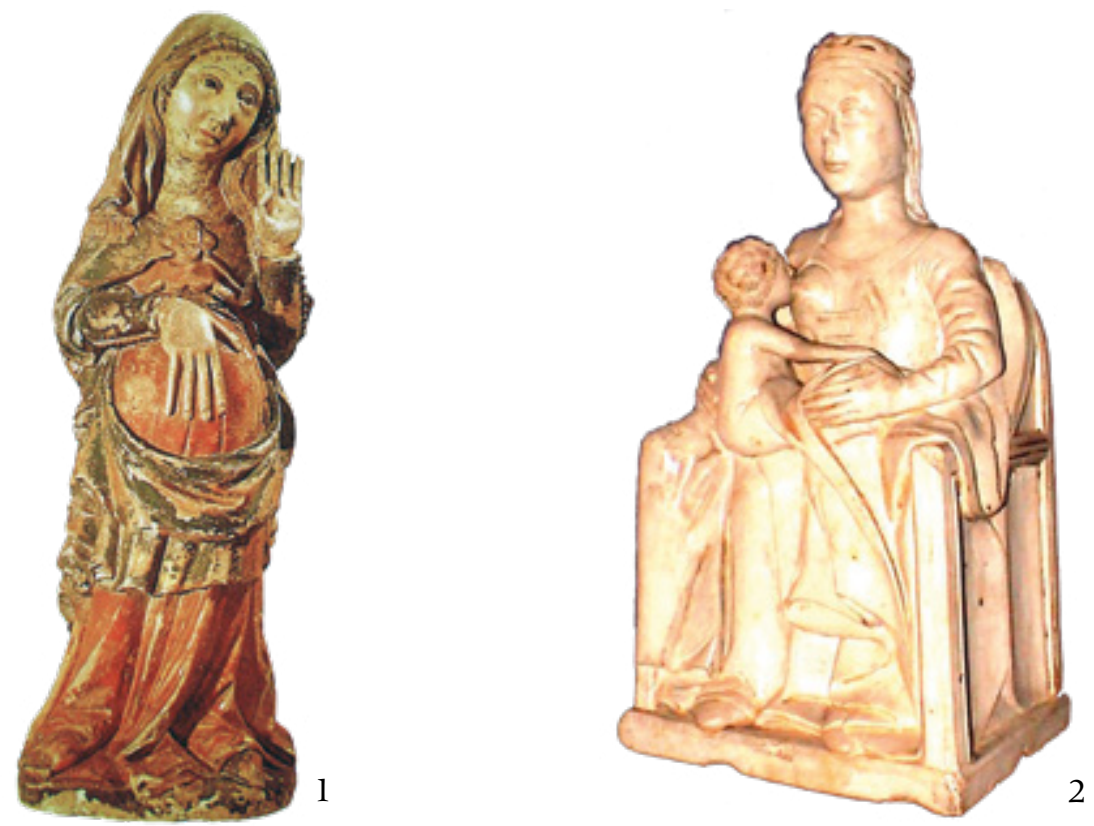

Illustration 1. Virgin of Expectation, fouteenth century, Lisbon, National Museum of Arte Antiga (H. 91 x L.25,5 x P. 6 CM). Picture by the author.

Illustration 2. Virgin of Milk, fifteenth century, Guimarães, Museum of Alberto Sampaio (H. 38 x L. 21 x P. 15,5 CM ). Picture by the AUthor.

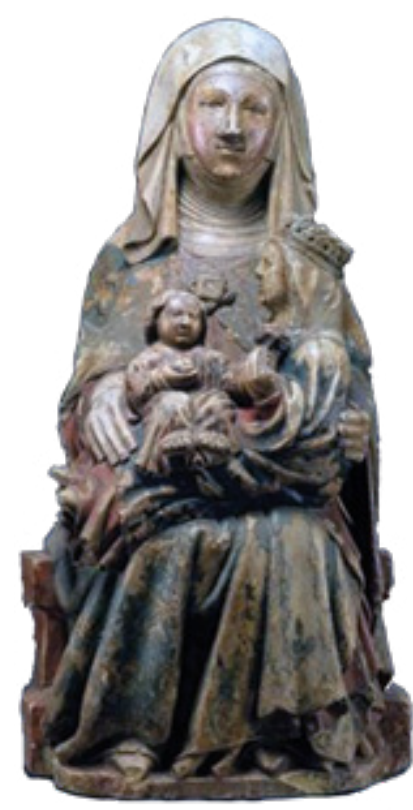

Illustration 3. Holy Mothers, Santa Ana with the Virgin and the little Christ, fifteenth century, Lisbon, National Museum of Arte Antiga, Col. Comandante Ernesto Vilhena (H. 73 x L. 37 x P. 28 CM). Picture by the Author. 
in the parturient's room was locked by a veil of secrecy and shame that neither the husband nor the physician could easily access.

As women generally did not write down or record their lives, the literate medieval information about the transmission of life is very scarce, being almost all of it concentrated in three types of sources: medical and scientific treatises, moral education manuals for women and hagiographies and books of miracles. I am going to address the first one: the scientific and medical treatises, more specifically the Medical Works of the Portuguese Pedro Hispano, ${ }^{5}$ the Hispanic Arabic compendium of obstetrics and paediatrics, known as Book of the Generation of the Fetus ${ }^{6}$ and the manual written in French by Aldebrandino de Siena, under the title Le Régime du Corps. ${ }^{7}$ All of them compile knowledge, techniques and regulations regarding pregnancy, childbirth and the care of the newborn, though we do not know whether they were practices socially followed or not.

\section{Pregnancy}

A sterile marriage left the couple under suspicion either of using contraceptives, performing abortion or practicing infanticide, or engaging in sexual pleasures not directed to their only legitimate function - the procreation. A good marriage should be prolific and a good wife should be a mother.

Infertility, usually attributed to women, could be cause for marital repudiation. Thus, from pilgrimages to the shrines of devotion, use of relics previously belonging to saints, prayers, invocations, promises, to the use of many and varied miracle potions, everything was done so that the woman could conceive. ${ }^{8}$

Medical treatises begin with the enumeration of the several problems associated with sterility, followed by advices and recipes to encourage the development of pregnancy, recommending temporal and positional prescriptions, food and dietary regimes to correct the excesses of heat or dryness that were considered causes of sterility, as well as many home potions to be applied on the woman's body, usually mixing animal, vegetable and mineral elements. For instance, donkey's milk, deer's horn or elephant's urine, incense, lemon balm or mint, alum, myrrh or gypsum. ${ }^{9}$ It is interesting to analyse what medieval texts say about the woman's body. Most of those texts were written by men, many of whom were clergy and members of the

5. Hispano, Pedro. Obras Médicas, ed. Maria Helena da Rocha Pereira. Coimbra: Universidade de Coimbra, 1973.

6. Ibn Sa'id, Árib. El libro de la generación del feto, el tratamiento de las mujeres embarazadas y de los recien nacidos (Tratado de Obstetricia y Pediatria hispano árabe del siglo X), ed. Antonio Arjona Castro. Cordoba: Pons, 1983.

7. De Siena, Aldebrandino. Le Régime du corps, eds. Louis Landouzy, Roger Pépin. Paris: Champion, 1911. 8. About sterility, see: Rodrigues Oliveira, Ana. A Criança...: 48-58 and Rodrigues Oliveira, Ana. $O$ dia-adia...: 15-20.

9. Hispano, Pedro. Obras Médicas...: 234-238, 242 and 262-270. 
church who had taken a vow of celibacy and thus could neither have sex or, as men, enter the birthing chamber. Many of them believed that the female sexual organs were male organs turned inwards. Women were deemed subordinate to men as their sexual organs had not grown outside of the body and so were not fully formed or developed. In essence, they were inferior versions of men.

Some people even believed that they could choose the sex of their baby by the types of foods they ate, the infusions they drank, the positions they should have during sexual intercourses or a kind of medicines they invented. To generate twins there were recipes, as well; one of them was to drink, in equal parts, by man and woman, a liquid obtained by mixing cooked and dried asparagus, goat's milk, cow's milk, honey, and pepper. Another one recommended the ingestion, by the future mother, of a preparation of ground ginger mixed with milk of woman, donkey and camel in equal parts. They had no concept that it was the male sperm that dictated the sex of the child. It all laid heavily upon the woman's shoulders. ${ }^{10}$

For Hildegarda of Bingen, the german naturalist and mystical Abbess of the twelfth century, if it was the force of the male seed that determined the sex of the embryo, it would be the love between the child's parents that would determine the moral qualities that the child would have. Thus, a great love between the spouses and a strong or weak masculine seed would, respectively, generate a virtuous boy or a virtuous girl. The lack of love between the couple would generate a bad son or a bad daughter. ${ }^{11}$

Initially, some women would not have even known they were pregnant until they felt the first movement of their baby inside them: the fetus of a boy would begin to move around three months, the fetus of a girl would begin to move a month later. ${ }^{12}$ A women's lack of regular menstruation could be related to several factors including illness, breastfeeding, excessive fasting or even a poor diet. It may seems amazing to us that a woman would not know that she was pregnant for several months, but there were no reliable tests for pregnancy during this period. One pregnancy test was to examine the colour of the urine and if it was a pale yellow to white colour with a cloudy surface, the woman could be pregnant. Other tests involved examining a needle left in the woman's urine to see if it rusted, or seeing what happened when wine was mixed with the woman's urine. Also if the woman had drunk water with honey before going to bed and during the night she felt pain around the navel or if she had put a garlic in the vagina before falling asleep and the next morning still smelled of garlic, she was surely pregnant. ${ }^{13}$

The appearance and posture of the expectant mother denoted the sex of the unborn child. Therefore, if she had a beautiful and a cheerful face, a clean skin, and light movements, all would indicate that a boy would be born, because he reinforced the mother's warmth while activated her senses and facilitated her movements. A

10. Rodrigues Oliveira, Ana. A Criança...: 53-58.

11. Thomasset, Claude. "Da natureza feminina”, História das Mulheres, 5 vols., Georges Duby, Michelle Perrot, eds. Porto: Afrontamento, 1993: II, 84.

12. Ibn Sa'id, Árib. El libro...: 68-73.

13. Ibn Sa'id, Árib. El libro...: 68. 
maternal skin with dark spots, accompanied by sunken eyes and numb movements and senses would indicate a girl, because she brought the cold that altered the mother's skin and cooled her blood. It was also possible to know the sex of the child to be born by the future mother's walk: if she laid all the weight of her body on her heels, it would be a boy; if she unloaded it on her toes, she expected a girl. ${ }^{14}$

Since pregnancy was a risk and its end unknown, once having reached the desired fertilization, a set of recommendations and requirements to be considered for a successful pregnancy came forward. The vulnerability of pregnant women to many infections and diseases worsened the already poor conditions of gestation of the fetus, among which, especially for socially disadvantaged groups of women, were the violent work and the malnutrition that caused many miscarriages. Enemas, ointments and several types of food were part of the medical prescriptions that sought to prevent the multiple causes of abortions, such as falls, excessive fatigue, sadness, anxiety, weakness of the uterus or of the sperm, hunger, blood flow or even diarrhoea. Therefore, the medical treatises proved to be very careful with all these symptoms. Thus, if the woman got sick and her breasts suddenly got smaller, an abortion should, most certainly, be expected; if milk dripped from the breasts, it also meant that the fetus was weak. The sunken eyes, the face, the body and the swollen feet, the white nose and ears as well as the greenish lips also indicated the birth of a stillborn baby or of a child who could only survive for a short time after being born. ${ }^{15}$ Such a great attention given by medical treatises to the gestation period is also due to the high infant mortality rates at the time, which, in Portugal, reached values that were close to the 30 per cent in the rural areas and to the 12 per cent in the urban areas or cities. ${ }^{16}$

In the medieval medicine treatises, a great attention to the eating habits of the pregnant was also granted, since the health of the fetus was not indifferent to the nourishment habits of his genitor. Accordingly, doctors recommended that the mother should be properly fed and avoid salty or bitter food, otherwise, the child could be born without nails or hair and even more sensitive to diseases. Spices, including salt and pepper, could cause leprosy. Some meats were also forbidden, being the white meat particularly recommended. Heavy meals were strongly inadvisable. However, to this diet, with no salt or stimulants, energy and sugary drinks could be added; wine was completely forbidden, because if the expectant mother drank it, the child could become epileptic. The hunger of the pregnant was also referred as hurting the developing fetus, since, without food the mother's stomach grabbed dangerous bodily secretions, leading to nauseas, pains and lack of appetite that would weaken her blood. It was advised that, although the pregnant should eat and drink with moderation, she should live happily so that these good habits could be transmitted to the fetus.

14. Ibn Sa'id, Árib. El libro...: 59-60.

15. Ibn Sa'id, Árib. El libro...: 91-93.

16. Coelho, Maria Helena. "Os homens ao longo do tempo e do espaço", Portugal em definição de fronteiras (1096-1325). Do Condado Portucalense à Crise do Século XIV, Maria Helena Cruz Coelho, Armando Luís Carvalho Homem, eds. Lisbon: Presença, 1996: 180-182. 
The first forty days of pregnancy were the most dangerous for abortion. During this time, it was recommended both to avoid sudden movements, jumps and dangerous foods as well as moderation in baths and body washes, while, at the same time, it drew attention to the harm that violent sneezing could do. Therefore, several prescriptions were provided for stomach disorder, vomiting and abnormal appetites. Nevertheless, after the seventh month, frequent baths and laxative food were advised to prevent pregnant women from the labor pains. ${ }^{17}$

\section{During Labor}

The cares during childbirth, the last stage of an uncertain journey, deserved particular attention.

In preparation for the child's arrival, women kept the birthing room warmed and clean, or purified with scented herbs. It should be closed off and, if possible, tapestries would be hung over the windows to block out as much light from the outside world as possible. The idea was to recreate the womb: warm, dark and quiet. Only a single window would have been left open to allow fresh air into the room and only a small amount of light, as it was believed that too much light could damage the expectant mother's eyes.

When the pains started, the pregnant woman was advised to walk slowly and to take some rest breaks. During the birth itself, the presence of the midwife, a traditional birth attendant, was suggested; she should be sitting in front of the pregnant woman, with her nails well clipped to better feel the placenta and receive the baby. It was advisable that three more women were present: two on each side of the mother to hold her tight, to cheer her up, to encourage and comfort her; the third one, behind, to hold her when she leaned back (see figure 4). The midwife's central role was safely to deliver a mother's unborn child. To ease her pain and bring her to a quicker parturition, the midwife would rub her patient's belly with a salve.

The birthing room was the domain of women, where midwives or other women who were mothers assisted the delivery and encourage the mother. The presence of a doctor with the woman in labor very rarely should occur, not only for reasons of decency (these were women matters), but also because their small number tended to concentrate them on more serious issues and in the main population centers. Labor was thus a private and domestic event.

Various positions are known to give birth, such as sitting in birthing stools or chairs supported by their female companions (see figure 5) or being on their knees (see figure 6).

At the moment of the expulsion of the child, the midwife was advised to carefully try to take the head before the members and, at the same time, to act in order to

17. Ibn Sa'id, Árib. El libro...: 87-91 and Thomasset, Claude. “Da natureza feminina"...: 164. 


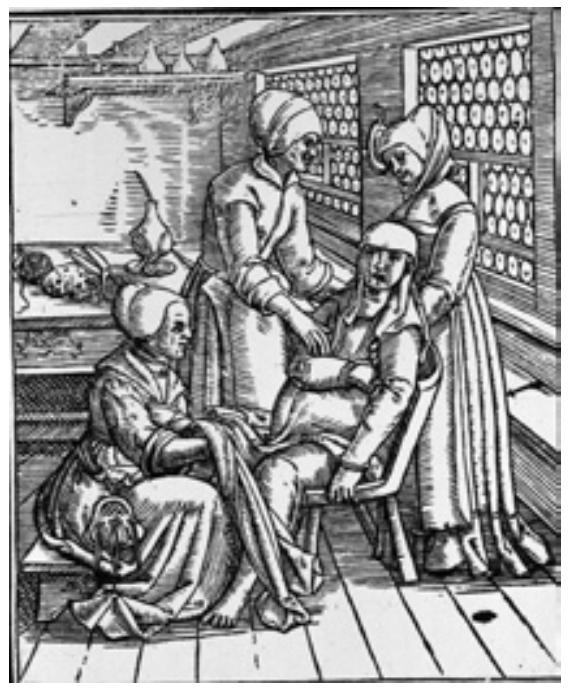

ILLUSTRATION 4. JAKOB RUEFF (CA. 15001558), Three MIDWIVES ATTENDING TO A PREGNANT WOMAN, 1554, FROM <HTTPS://COLLECTIONS.NLM.NIH.GOV/ CATALOG/NLM:NLMUID - 101436177 IMG $>$.

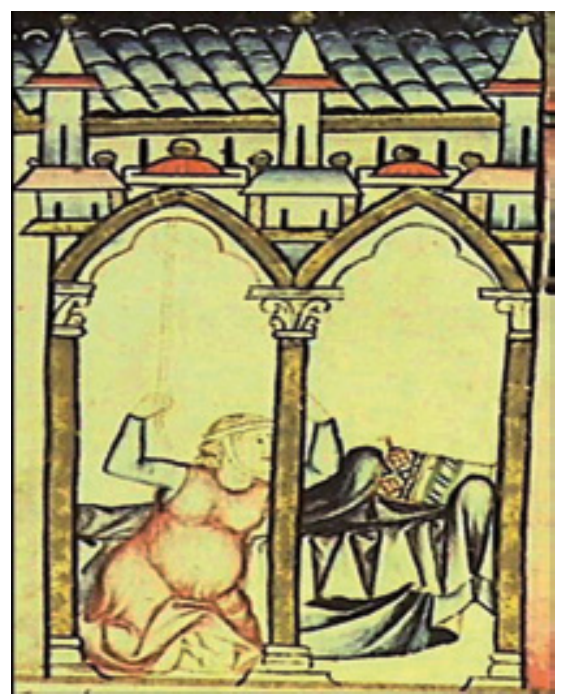

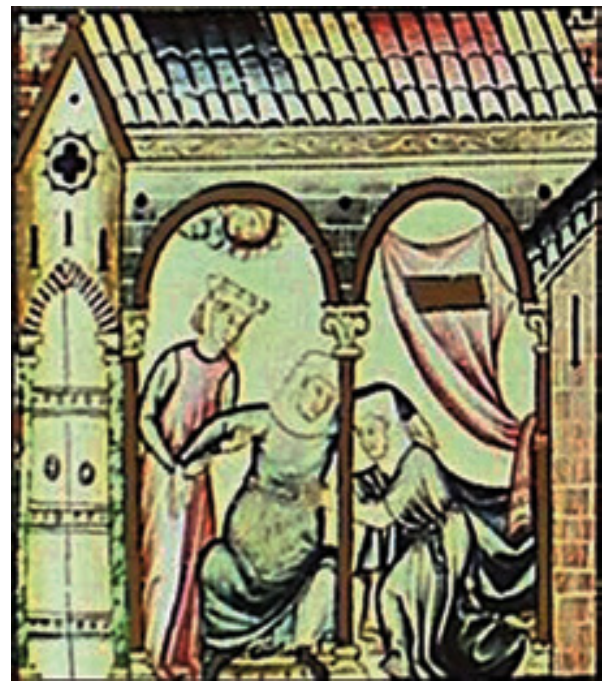

Illustration 5. Giving BIRTH SitTed, Miniature, thirteenth Century, San Lorenzo de El Escorial. Real Biblioteca del Monasterio de San Lorenzo de El Escorial, MS. T.I.1, Cantiga 89. Picture BY THE AUTHOR.
Illustration 6. Giving BIRTH ON KNEES, Miniature, thirTEenth CENTURY, SAN LoRenzo de El Escorial. Real Biblioteca del Monasterio de San Lorenzo de El Escorial, MS. T.I.1, Cantiga 17. Picture by the author. 
avoid any deformations. ${ }^{18}$ There was no way of monitoring the baby's heart rate or to take blood pressures, and thus women relied heavily upon other experienced women to support and help them. If the labor was difficult or dangerous, which it often was, many options were available for the woman who was giving birth but none were particularly effective. Largely these consisted of herbal poultices, folk remedies and devout prayer. In fact, women often clutched holy relics, images, icons or recited religious prayers and chants to help them and give them strength throughout the birthing process. Amulets and amber could also be placed upon the mother's stomach, or prayer rolls could be read or even wrapped around the stomach to help with the pain of labor and to aid safe delivery of a baby.

Among the women of the various social groups, objects and amulets of various natures, that were believed to help in this difficult and uncertain moment, were used and lent. Queen Isabel of Aragon, in her testament of 1327, left to the convent of Santa Clara, in Coimbra, a Virgin with the Child that, for being focused on Mary's maternity, would be considered a good omen for both marriage and procreation. This image would be loaned to women who needed it and returned to the convent thereafter. (see figure 7). Equally, the queen D. Beatriz, the queen of the Portuguese king Afonso IV, left in testament to her grandson, the future king D. Fernando, a gold cup with the image of Agnus Dei that, among other attributes, was believed to provide a good childbirth.

Many women invoked the Virgin of Expectation or Saint Margaret, the patron saint of pregnant women and childbirth. Saint Margaret had been eaten by a dragon but managed to get out of his womb due to the crucifix she was holding. It was hoped that babies would be delivered as easily as Saint Margaret had come out of the dragon (see figure 8).

Although physically these things could not have assisted in the birth, the faith and belief that women had would have helped them psychologically and could have helped them to deal with their fear and worries over childbirth. The pain associated with labor and childbirth was thought to be due to Eve's sin in the Garden of Eden. Her original sin meant that all women had to suffer great pain and many women turned to religion to provide them with the support and relief they greatly desired. There was also the strong possibility that a mother in labor could die, so religion and faith played a hugely important role in everyday life and also within the childbirth. Young mothers, older mothers, poor or rich mothers, all could die not only in giving birth but also due to complications afterwards. The process was so risky that women were urged to confess their sins and to write their wills before they gave birth in case they could not survive the delivery.

Childbirth was, undoubtedly, a mix of emotions - pain, fear, anxiety, anguish, despair, but also hope and love.

18. Ibn Sa'id, Árib. El libro...: 96-106. 


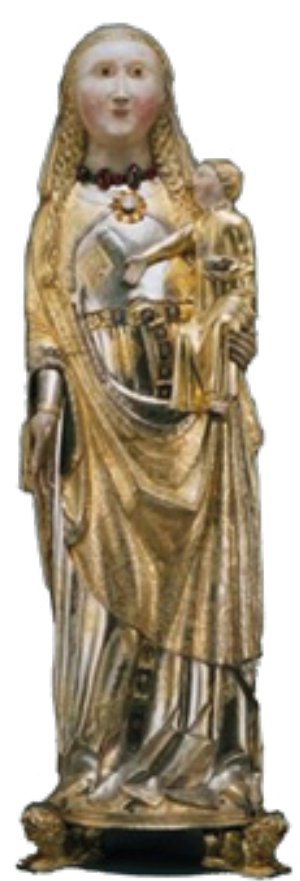

IlLuSTRATION 7. The Virgin AND THE CHILD, FOURTEENTH CENTURY, Coimbra, National Museum Machado de Castro, Treasure of Queen D. Isabel. Picture by THE AUTHOR.

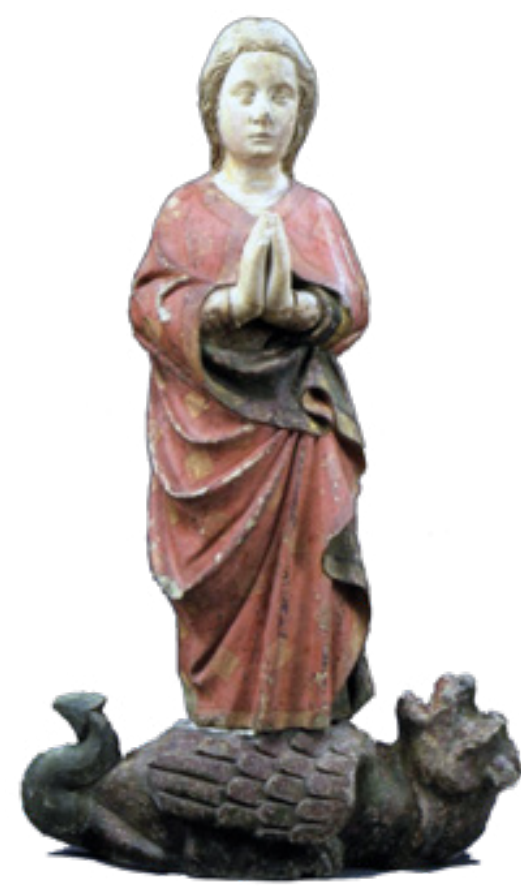

ILlustration 8. SAint Margaret, FifTEEnth century, Lisbon, National Museum of Arte Antiga, Col. Comandante Ernesto Vilhena (H. 68,5 x L. 44,5 x P. 20cm). Picture By THE AUTHOR.

\section{The Birth Assistants}

Throughout all this process, the midwives played an important and decisive role. Their medical training was, most certainly, quite elementary, making special use of the knowledge and techniques that experience and tradition had taught them. Some of them had years of experience delivering babies and thus had a great expertise. A candidate for midwifery usually learned from an older experienced midwife, and from her she usually acquired the necessary information and direction for her specialized duties.

However, considering that some treatises included specific instructions specially addressed to the midwives, as well as many illustrations of the many positions the fetus could take at birth, (see figure $9-1,2,3-$ ) we are led to believe that some of 

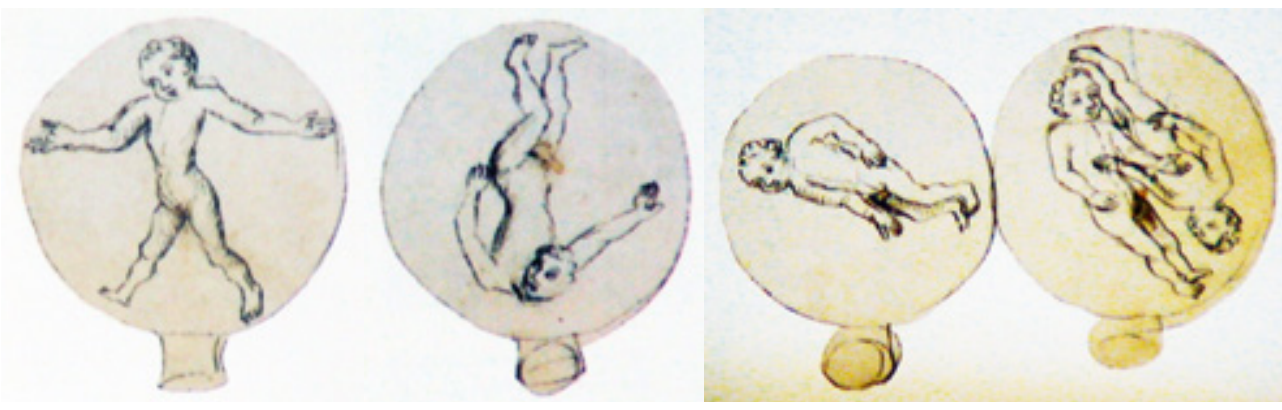

Illustration 9. Illustrations of foetal positions in the womb. Miniatures, thirteenth Century, Paris, Bibliothèque nationale de France, Collection of medical treatises, MS LATIN 7056, F. 88v-89R. PictURe By the AUthor.

them were literate, or, at least, were able to read. In such situations, the medical textbooks recalled us how midwives should be careful and have great experience, also suggesting several ways on how to deal with the various positions taken by the baby at birth, advising them to force him to take the right position, showing them how, while they should treat carefully the part of the body already out, they would have to handle, carefully and smoothly, the part of the little human being still inside the mother's womb, since it was very common the difficult births to end up with decapitated fetuses or dead children in their mothers' wombs.

Facing the difficulty or impossibility of a vaginal delivery, a caesarean birth could be tried, although its techniques were still highly unreliable (see figure 10). The role and responsibility of midwives were essential for the decision and implementation of a caesarean section. It was their responsibility to evaluate the real death of the parturient and the choice of the right moment for the caesarean, since the possibility of saving the child was dependent of a short period of time between the confirmation of the mother's death and the surgical intervention. This situation was often not easy to fulfil, since complicated childbirths lasted for several days, through successive episodes of exhaustion and loss of consciousness, and it was difficult to assess the exact moment of death of the pregnant woman. Notwithstanding, they were done, in general, post-mortem, aiming the baptism of the unborn children whose mothers had died during childbirth, even though their chances of survival were very low. The loss of a child, no matter the time, is a traumatic experience that has huge emotional impacts upon the family.

In fact, medieval birth attendants faced a lot of pressure. Not only they had to do their best to help the mother and the baby to survive the birth, but they were also responsible for the newborn's soul. If they fear the infant's life was in danger they must baptize him before he dies so his soul could go to heaven. Given the high rate of child mortality, the concern for the salvation of children's souls has forced 


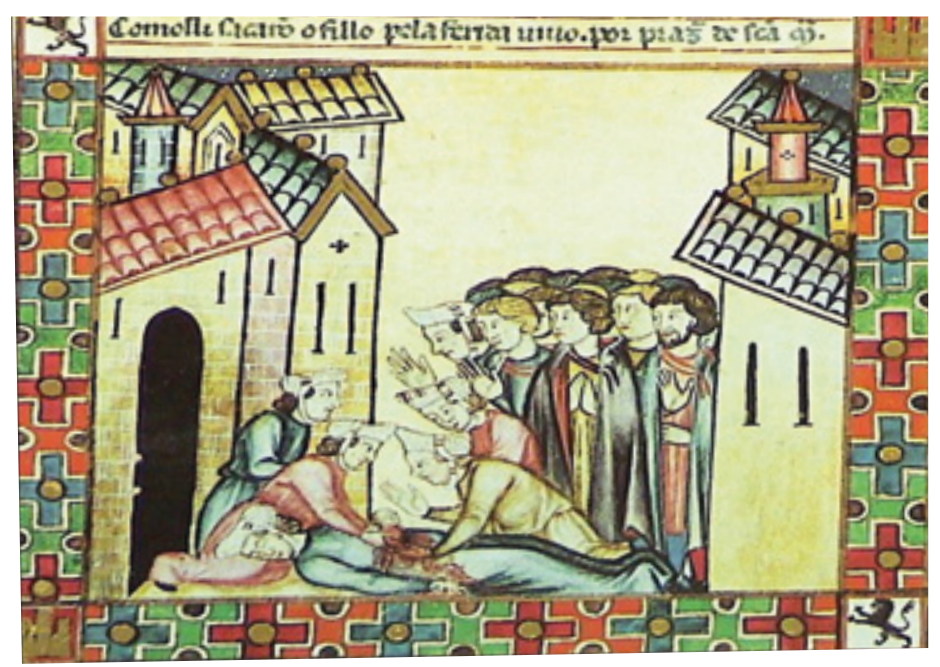

Illustration 10. Caesarean birth, Miniature, thirteenth Century, San Lorenzo de El Escorial. Real Biblioteca del Monasterio de San Lorenzo de El Escorial, MS. T.I.1, cantiga 184. Picture by THE AUTHOR.

ecclesiastical acceptance that, in the event of a child's death, the baptism could be done without a priest and by a layperson who knew how to do it. If the child survived, baptism should be confirmed by a priest. ${ }^{19}$

The act of baptism would remove the natural sin and cleanse the soul; it was the only time that a woman was ever allowed to deliver one of the sacraments but only to be done if the child was going to die. The correct recitation of the formula before the moment of death was vital for the salvation of the baby's soul. In fact, if a birth attendant failed to baptise an infant quickly enough before his death, or forgot a word or phrase of the formula, she would be tempted to lie in order to allow the infant to be buried in sanctified ground and reassure the parents that the child's soul was not lost. Their ability to perform baptism was, certainly, one of their sadder duties.

In addition to cases of death, complicated deliveries were also responsible for the birth of children with serious health problems or physical-anatomical deformations. There was a very strong feeling that malformed babies indicated a sin committed by their parents, particularly some kind of sexual deviation, such as having sexual intercourses at times proscribed by penitentials, for instance, Sundays, during Lent or during the woman's menstrual period. In this last case, women could generate red

19. About the baptism in medieval times, see: Rodrigues Oliveira, Ana. O dia-a-dia...: 39-43. 
haired and tendentially leprous children, given the efforts of the fetuses to get rid of the maternal menstrual blood that would be contained in their porous members. ${ }^{20}$

Some medical treatises, however, attributed this situation not to a complication of childbirth but to a badly constituted uterus. Thus, if the child was born deformed, this was due to the fact that it was a product of a deformed mold that prevented the correct development of the male sperm. ${ }^{21}$

\section{After Childbirth}

To born was, however, only a first obstacle to overcome: the spectre of death continued to haunt the little being that had just left the warmth of the womb and come into a new life and to a world full of adversity. Fearing that, during the first days of life, the fragility of the child would not resist to the changes that his body would inevitably come through, the medical treatises recommended that he should be well treated, protected and strengthened, explaining how the newly born child should be lightly received by the hands of the midwife and immediately placed on a dry cloth and gently warmed to protect him from the cold. Then, it was prescribed the practice of movements to stimulate and test the joints, and, for that, the midwife was advised to bend and extend the limbs of the child.

The bath followed, and the same texts had also guidelines about the precepts after that. They explained how the midwife ought to hold the baby with her left arm and wash him using the right hand, being always attentive to prevent the water from entering into the child's ears. The midwife's finger wet with aromatic oil was advised to clean the baby's drool and the inside of his mouth, especially the tongue and gums. The child should only be removed from the bath when his body was red and hot, and then he should be dried with a soft cloth. His body should then be massaged with oil by the midwife.

After the bath, it was advised to cover the wound in the navel with a bandage, to cut the nails and to put eye drops, all of these done with great care and gentleness. ${ }^{22}$ The child was then ready to be wrapped in swaddling clothes and bands of lightweight fabric, usually a strip of linen. This was believed to provide warmth, encourage the baby's limbs to grow straight and vital to prevent the newborn from an always feared and unintended deformation of the body. One common belief was that the limbs were loosely-jointed and that sudden movements were harmful to the development of the child.

Swaddling clothes generally consisted of a square of cloth with two or more additional bandages for securing. The baby was laid on the cloth diagonally and the corners were folded over the body and the feet and under the head with the

20. Rodrigues Oliveira, Ana. O dia-a-dia...: 23-24.

21. Ibn Sa'id, Árib. El libro...: 82.

22. Ibn Sa'id, Árib. El libro...: 102-104, $111-112$. 
bandages being tied securely around the baby. This formed the baby's clothing until it was about eight or nine months old (see figures 11 and 12).

Following the positions taken by Philippe Aries, ${ }^{23}$ several investigators have considered the children's dressing and swaddling as a confirmation of the alleged medieval affective indifference of parents for their children, caring little about their healthy development. ${ }^{24}$ Nowadays, such an opinion seems too biased and prejudiced. On the contrary, regardless of any harm that this practice might have caused in their growth, it prevented the children to become injured or bitten by animals which shared the streets and the human houses, also avoiding the malformations resulting from excessive kicking or the hernias caused by convulsive sobs. $^{25}$

\section{Caring for baby's food}

In the fifteenth century, the treatises of child health gave particular importance to the nutritional care of the newborns. Therefore, they advised that, before eating, the child's stomach should be cleaned by sucking the mother's finger previously dipped in honey with no foam. The mother, herself, should breastfeed the child, at least in his first four days. Only after that, if needed, she can be replaced by a wet nurse (nanny). ${ }^{26}$ According to the doctors' opinion, it was through the breast milk that the virtues of the mother and of her lineage were transmitted. Equally relevant is the theory that breast milk is the result of the transformation of the blood which had fed the child during pregnancy. ${ }^{27}$ Also the Church felt that if the Virgin breastfed his own child, then noble women should do likewise. The proliferation of images of the Virgin of Milk since the thirteenth century has contributed to the progressive valuation of the importance of breastfeeding and of a new ideal of motherhood, more nourishing and protective than merely reproductive.

Despite all this, many noble women were often not too involved in the direct upbringing of their babies, preferring to hire the services of a wet nurse instead of breastfeeding the children themselves. Given the high child mortality that occurred even in the privileged social groups, it was necessary to have many children to ensure the preservation of the lineage and the succession. Taking

\footnotetext{
23. Ariès, Philippe. A criança e a vida familiar no Antigo Regime. Lisbon: Relógio d'Agua, 1988.

24. Hunt, David. Parents and Children in History: The Psychology of Family Life in Early Modern France. New York: Harper Torchbooks, 1972; DeMause, Lloyd. "The Evolution of Childhood", The History of Childhood. The Untold Story of Child Abuse, Lloyd DeMause, ed. New York: Peter Bedrick Books, 1988.

25. Rodrigues Oliveira, Ana. A Criança...: 101.

26. See Roy, Emile. "Un regime de santé du XV siècle pour les petits enfants et l'hygiène de Gargantua", Mélanges offerts à E. Picot. Paris: 1913: I, 153; Ibn Sa'id, Árib. El libro...: 103.

27. Alexandre-Bidon, Danièle; Lett, Didier. Les enfants au Moyen Âge (Ve. - XVe. siècles). Paris: Hachette, 1997: 123 and 263.
} 

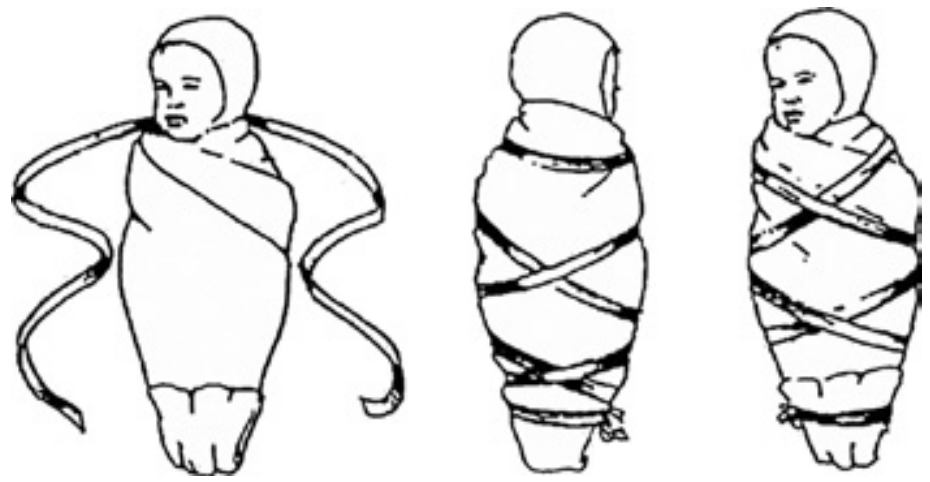

Illustration 11 . Design by R. Kitabgi (Textile-Arts). Bidon, Alexandre; Closson, Monique. L'enfant à l'ombre des cathédrales. Lyon: Presses universitaIRES DE Lyon, 1985: 96.

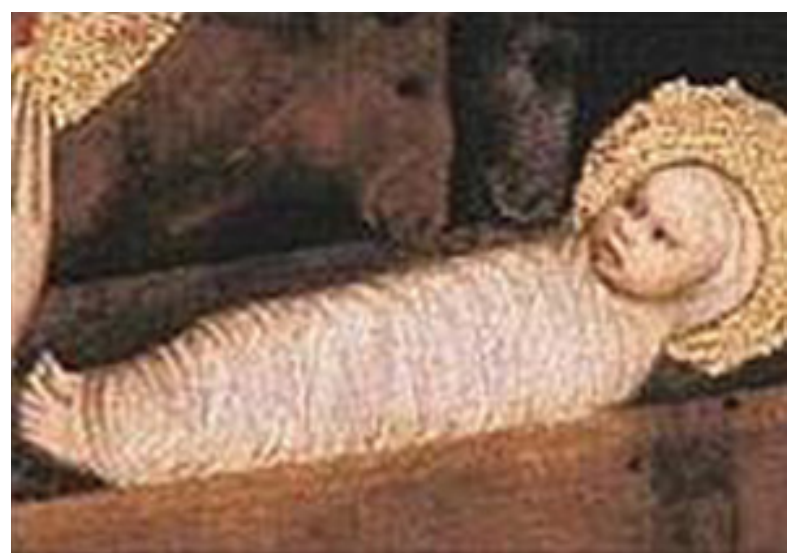

Illustration 12. Master of the TŘeboñ Altarpiece, The Adoration of Jesus, c. 1380, Hulboká, Alsova Jihoceska Galeria. The DetaIl From the TŘEBoň SHOWS the BABE SNUGLY WRAPPED FROM TIP tO TOES. PictURE By THE AUtHOR. 
into consideration that breastfeeding, if prolonged, provided, in statistical terms, greater difficulty in getting pregnant breastfeeding was discouraged to noble women. Soon after birth, in order for a new maternity cycle to begin, the breast milk should be dried.

If the option was to have a wet nurse, then the choice should follow very strict criteria. Firstly, she had to fulfil some physical requirements. Doctors and educators shared the opinion that she must look like the biological mother, be healthy enough and aged between twenty-five and thirty-five years old. Wet nurses having big breasts were not advisable taking into account the prevention of malformations in the baby's face. ${ }^{28}$ Having one or more children was considered an advantage because it could mean better milk.

Moreover, the choice of wet nurse also required the evaluation of certain behavioural qualities. They should not, for example, be angry, sad, fearful or silly. Similarly they should not be too talkative so that the child being breastfed would not acquire such habit. They should, however, be able to sing songs for rocking and comforting the baby. Then, while exercising their functions, they should be supervised to ensure that they would not harm the children entrusted to them. Therefore, it was advisable to assure that they would neither eat salty, spicy or acidic foods, as well as old meats and spices, nor drink pure wine because these could harm the child's brain. On the other hand they were recommended to consume enough rice, fresh fish, lots of raw or boiled milk, and the right amount of water that helped her milk not to become too thin or thick.

Finally, foreign travels were avoided, so that fatigue did not diminish the quality of the food supplied and, especially, the prohibition of any sexual intercourses, as any pregnancy would divert to the unborn baby the blood due to strengthen the milk of breastfeeding. ${ }^{29}$

The wet nurses took the mother's place in many different areas such as giving affection to the baby they were taking care of, bathing the baby, singing lullabies, comforting the baby when he fell or when he was sick, and sometimes even chewed the baby's bread or meat.

In fact, the weaning stage should be done gradually; it was recommended to start by the ingestion of bread previously chewed by the wet nurse, being progressively replaced by a crust of bread, honey and milk. It was advisable to start this new diet around the age of two and not be started in the hot months, in order to avoid gastrointestinal problems since the weaning stage coincided with a period of marked morbidity. ${ }^{30}$

28. De Siena, Aldobrandino. Le Régime du corps...: 77.

29. Alexandre-Bidon, Danièle; Lett, Didier. Les enfants au Moyen Âge...: 124. About the generality of the care to be taken with the choice of the wet nurse, see Ibn Sa'id, Árib. El libro...: 114-116.

30. About the baby's nutrition, see: Rodrigues Oliveira, Ana. A Criança...: 104-111. 


\section{The baby begins to walk and to speak}

Soon came the time when the child began to move and wanted to explore the space by himself, gradually developing his autonomy. Starting to walk meant an important step in this new phase. The age of a year or so, was mentioned as desirable to start walking, since before that, his members were so fragile that they could easily twist or break. To prevent this, it was even recommended that the children should not be allowed to walk too much, nor to stand for too long before they were seven years old. ${ }^{31}$ The use of a wooden walker, to help the child moving was advised (see figure 13).

As for the learning and development of the child speaking, the medieval medical treatises considered essential the care with the teething, since the correct or the poor and incomprehensible articulation of the first words were dependent on the teeth. Consequently, they prescribed the massage of gums with butter, chicken fat, or even roast hare brains, in order to bring up and develop a healthy dentition. Then, as soon the child began to babble his first words, his mouth should be rubbed with rock salt and honey, as well as washed with barley water, to strength the teeth and prepare the proper functioning of bone and muscle joints of the oral cavity. ${ }^{32}$

Finally, aiming the learning of words, suggestions were given to start with the easiest to pronounce, or with those not needing many tongue movements, such as 'Mom' and 'Daddy'.

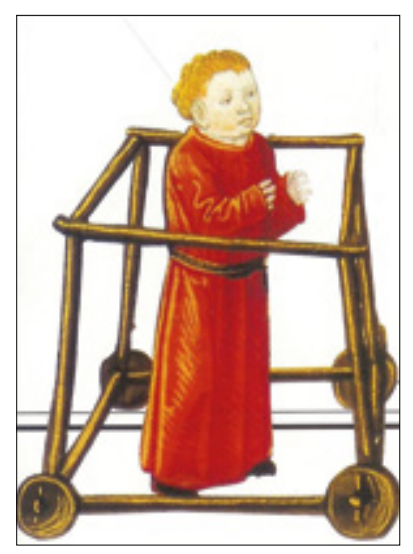

Illustration 13. Angelicus the Bartholomeus, Livre des Propriétés des Choses, fifteenth Century, Paris, Bibliothèque national de France, MS Frs 218, f. 95. WoOden WALKer to HELP THE CHILD MOVING, DETAIL OF A Miniature. Picture by the AUthor.

31. De Siena, Aldobrandino. Le Régime du corps...: 78.

32. Riché, Pierre; Alexandre-Bidon, Danièle. L'enfance au Moyen Age. Paris : Éditions du Seuil-Bibliothèque nationale de France, 1994: 81. 


\section{The baby's diseases}

The death of children was embedded in the social daily life of Middle Ages. Many children died before they even lived for a full year. Generally, most infant deaths occurred as a result of accidents or disease. Undoubtedly, children who came from poorer families experienced a higher rate of infant mortality because it was harder for poorer families to obtain medical help or health care. Nevertheless, few were the families, even those of the elites, who have not suffered the loss of one or more children before adolescence. According to the Lecturer Oliveira Marques, the number of surviving children of a Portuguese family from the twelfth to the fourteenth centuries would be, on average, two, being common the households in which only one child went beyond the majority. ${ }^{33}$

Therefore, the medieval medical treatises considers an amount of advices and therapies to prevent the most common diseases connected with the successive stages of child development from birth until the permanent teeth came up.

Concerning the early life of the child during his forty days after birth, they draw attention to the dangers of thrush in the mouth or tongue and to the vomiting caused by nutrition problems due to the fact that the child started to be fed by mouth instead of being fed through the umbilical cord. Cough was also referred, remembering the need to guarantee to the little baby a not too dry atmosphere and a mild climate similar to the womb.

In addition to these disorders, the beginning of children's lives was also related to insomnia and night terrors attributed to a heavy stomach by excessive breastfeeding. Thus, not only was advised to decrease the amount of milk to be ingested by the baby, as well suggested to the wet nurse, to do everything to improve the quality of her milk. It was also recommended to always have near the child water with boiled violets, considered as tranquilizer, or to grease his nose with violet oil mixed with a little saffron.

In those first months of life, the diseases caused by infections were worrying, such as the ones of the navel, worsened by the screams and the cries of the newborns, which were treated with egg white bandages placed on it for three days; also the ear infections, attributed to the excess of humors in the little child's brain, whose cure could be achieved by placing on the ears a wool sponge, soaked in water and honey. The pustules and rashes arising in the baby's head were treated by using a paste made of a mixture of several natural products put on the baby's shaved head. It was also ordered to those who breastfed the baby, to abstain from hot food, which burned blood and yellowed milk.

Having clarified the symptoms and treatments of all these early diseases, obstetricians and pediatricians are now focused on the health disturbances corresponding to a second stage of child growth, which is the one that ended at the age of seven months, with the appearance and consolidation of the first dentition. This brought the related pains, fevers and convulsions resulting from infections of

33. Oliveira Marques, António H. de. "A morte", A Sociedade Medieval Portuguesa. Lisbon: 1974: 210. 
wounds and swollen gums. To rush the appearance of the teeth, it was advised not only to relieve the pressure on the gums caused by feeding, but also to decrease the frequency and speed of feedings, and giving the body more energy and vitality, either by frequent hot baths or through the use of ointments to massage the gums. It was also recommended to those who were breastfeeding, to abstain from eating meat, drinking wine, having hot baths or making efforts that produced too much heat.

For cramps and diarrhea that weakened the child, it was suggested a variety of potions, from patches, brews, pills and powders to be taken by both the infant and the woman who nursed it.

At the same time, it is also considered a consequence of the first dentition, the possibility of brain damage or sense organs injuries, thus alerting for the screening of epilepsy and strabismus.

After the teething period, pediatricians felt that the health of children could become severely threatened when they began talking or when they stopped being breastfed. The first case was associated with the possibility of the appearance of tumors in the throat or bone deformities produced by the retreat of the occipital vertebrae, forcing the tonsils to move towards the nape preventing them from doing their function, which is to filter the residual blood still existing in the head.

Less theoretical and speculative, the problems related to poor child weaning refer mainly diseases of the urinary and digestive systems. The kidney problems are mentioned with regard to obstructive calculations for which are recommended hot water baths twice a day, among other therapies, to remove them. As far as the digestive system is concerned, intestinal parasites in connection with the appearance of worms are cited, presumably caused by the putrefaction of food in the stomach, and allergies described by the bubbles that spread throughout the body. That could be caused by the rubbing of clothing and corruption of the milk that took too long to be abandoned as children's nutrient.

Finally, having gone through the last step of the acquisition of permanent teeth, the pediatrics' treaties became significantly deficient and evasive, just noting the possibility of children to be disturbed by asthma, conjunctivitis, acute fevers, smallpox or measles, for which examination and treatment they advise consulting a general doctor. Thus we get into the medicine for adults, having to deal with manuals and treatises that were no more interested in children. ${ }^{34}$

\section{Conclusion}

Medieval medical treatises played an important role in medieval childhood recognition, multiplying and providing recommendations concerning breastfeeding 
and the best way to dress, lie down and feed the children. The medical discourse, at the same time normative and sensible, is essential to better understand how the medieval society considered childhood; in fact, in defining the specificity of the ages of life, they developed and released advices to protect and ensure the survival of their children.

For a long time it was thought that in a world where death took one out of three little children, these would only be regarded as lives on hold or deaths announced, to which great care and affection would not be granted. The consultation of multiple and varied sources made the medieval childhood came up differently. And if the care and concern for the child since its conception is visible in the normative, didactic, theological or canonical sources, among others, so it is in the medical sources. In fact, medieval medical treatises played an important role in medieval childhood recognition, multiplying and providing recommendations concerning breastfeeding and the best way to dress, lie down and feed the children. The medical discourse, at the same time normative and sensible, is essential to better understand how the medieval society considered childhood; defining the specificity of the ages of life, they developed and released advices to protect and ensure the survival of their children. 